\title{
Diagnóstico do gerenciamento de resíduos sólidos comerciais na região central de
}

\author{
Balsas - MA \\ Diagnosis of commercial solid waste management in the central region of Balsas - MA \\ Diagnóstico de gestión de residuos sólidos comerciales en la región central de Balsas - MA
}

Recebido: 05/07/2021 | Revisado: 09/08/2021 | Aceito: 10/08/2021 | Publicado: 14/08/2021

\author{
Kalia Auzier Martins Costa Coelho \\ ORCID: https://orcid.org/0000-0002-4513-4024 \\ Universidade Federal do Maranhão, Brasil \\ E-mail: kaliauzier@outlook.com \\ Taise Carvalho de Sousa \\ ORCID: https://orcid.org/0000-0001-9143-9008 \\ Universidade Federal do Maranhão, Brasil \\ E-mail: taisec.110@hotmail.com \\ Ana Paula de Melo Silva e Vaz \\ ORCID: https://orcid.org/0000-0001-9883-3614 \\ Universidade Federal do Maranhão, Brasil \\ E-mail: ana.vaz@ufma.br
}

\begin{abstract}
Resumo
Com a intensa urbanização brasileira, a temática relacionada aos resíduos sólidos ganhou destaque dentre os eixos estratégicos nos órgãos ambientais do país. Com a finalidade de solucionar os problemas socioambientais e econômicos gerados pelo acúmulo, destino e falta de tratamento adequado desses resíduos passou a ser obrigatório com a Lei $\mathrm{n}^{\mathrm{o}}$ 12.305/10 que institui a Política Nacional de Resíduos Sólidos. A lei destaca que a coleta, armazenamento, tratamento e disposição final dos resíduos sólidos não é competência somente do poder público, mas também dos grandes geradores. Nesse sentido, o objetivo do estudo foi identificar os grandes geradores da região central do Município de Balsas e fazer um levantamento da destinação dos resíduos sólidos produzidos por esses grandes geradores. A realização do estudo se deu por meio de pesquisa bibliográfica e documental, pesquisa de campo realizada em 43 estabelecimentos da área central. Por meio da pesquisa foi possível identificar o modo que o gerenciamento dos resíduos sólidos produzidos é realizado, considerando as etapas de acondicionamento, coleta e disposição final. Os resultados indicam que os resíduos sólidos produzidos pela maior parte dos estabelecimentos estão sendo tratados de forma negligente, tanto pelo poder público, quanto pelos grandes geradores. Portanto, com essa pesquisa foi possível compreender as reais necessidades do município para se adequar a Gestão Integrada de Resíduos Sólidos, conforme a legislação brasileira vigente, além de medidas que despertem a colaboração do município e da população para o melhor gerenciamento desses resíduos.
\end{abstract}

Palavras-chave: Grandes geradores; Resíduos sólidos; Política nacional dos resíduos sólidos.

\begin{abstract}
With the intense urbanization in Brazil, the theme related to solid waste gained prominence among the strategic axes in the country's environmental agencies. In order to solve the socio-environmental and economic problems generated by the accumulation, destination and lack of proper treatment of these wastes, it became mandatory with Law No. 12,305/10, which instituted the National Solid Waste Policy. The law highlights that the collection, storage, treatment and final disposal of solid waste is not only the responsibility of the public authorities, but also of the large generators. In this sense, the objective of the study was to identify the large generators in the central region of the Municipality of Balsas and to survey the destination of solid waste produced by these large generators. The study was carried out through bibliographic and documentary research, field research carried out in 43 establishments in the central area. Through the research, it was possible to identify the way in which the management of the solid waste produced is carried out, considering the stages of conditioning, collection and final disposal. The results indicate that the solid waste produced by most establishments is being treated negligently, both by the public authorities and by the large generators. Therefore, with this research it was possible to understand the real needs of the municipality to adapt to the Integrated Management of Solid Waste, according to the current Brazilian legislation, in addition to measures that arouse the collaboration of the municipality and the population for the better management of this waste.
\end{abstract}

Keywords: Large generators; Solid waste; National solid waste policy. 


\section{Resumen}

Con la intensa urbanización brasileña, el tema relacionado con los residuos sólidos ganó protagonismo entre los ejes estratégicos de las agencias ambientales del país. Con el fin de solucionar los problemas socioambientales y económicos que genera la acumulación, destino y falta de tratamiento adecuado de estos residuos, se hizo obligatorio con la Ley $\mathrm{N}^{\circ} 12.305$ / 10, que instituyó la Política Nacional de Residuos Sólidos. La ley destaca que la recolección, almacenamiento, tratamiento y disposición final de los residuos sólidos no es solo responsabilidad de las autoridades públicas, sino también de las grandes generadoras. En este sentido, el objetivo del estudio fue identificar los grandes generadores de la región central del Municipio de Balsas y relevar el destino de los residuos sólidos producidos por estos grandes generadores. El estudio se realizó mediante investigación bibliográfica y documental, investigación de campo realizada en 43 establecimientos de la zona central. A través de la investigación fue posible identificar la forma en que se realiza el manejo de los residuos sólidos producidos, considerando las etapas de acondicionamiento, recolección y disposición final. Los resultados indican que los residuos sólidos que producen la mayoría de los establecimientos están siendo tratados con negligencia, tanto por parte de las autoridades públicas como por las grandes generadoras. Por lo tanto, con esta investigación fue posible comprender las necesidades reales del municipio para adaptarse a la Gestión Integrada de Residuos Sólidos, de acuerdo con la legislación brasileña vigente, además de medidas que despierten la colaboración del municipio y la población para mejor. gestión de estos residuos.

Palabras clave: Grandes generadores; Residuos sólidos; Política nacional de residuos sólidos.

\section{Introdução}

A crescente geração de resíduos sólidos consolida-se como uma das muitas questões ambientais prementes do mundo contemporâneo. O aumento na geração desses resíduos é um fenômeno diretamente relacionado com o crescimento populacional e impactado por outros fatores intrínsecos ao comportamento social. O crescimento da economia que proporciona um aumento do poder aquisitivo da população traz consigo um maior consumo que, inevitavelmente, significa o aumento da geração de resíduos, principalmente em função do grande volume de materiais descartáveis colocados no mercado e da menor durabilidade dos bens e produtos comercializados (Abrelpe, 2012).

Um dos objetivos fundamentais estabelecidos pela Lei $n^{\circ} 12.305$ é a ordem de prioridade para a gestão dos resíduos, que deixa de ser voluntária e passa a ser obrigatória: não geração, redução, reutilização, reciclagem, tratamento dos resíduos sólidos e disposição final ambientalmente adequada dos rejeitos (Brasil, 2012). Entre os instrumentos definidos pela Política Nacional dos Resíduos Sólidos merecem destaque: os Planos Nacionais de Resíduos Sólidos; a coleta seletiva; os sistemas de logística reversa; o incentivo à criação e ao desenvolvimento de cooperativas e outras formas de associação dos catadores de materiais recicláveis.

De acordo com PNRS os estados terão que elaborar seus Planos Estaduais de Resíduos Sólidos para terem acesso aos recursos da União ou por ela controlados, destinados a limpeza urbana e serviços relacionados ao manejo de resíduos sólidos. O conteúdo mínimo do plano estadual é tratado no Art. 17 da Lei 12.305 (Brasil, 2012). Onde os planos Estaduais normalmente possuem os mesmos instrumentos da esfera federal, com ênfase em seu próprio território, e na definição de diretrizes para o planejamento e demais atividades de gestão de resíduos sólidos nas regiões metropolitanas, aglomerações e microrregiões, que têm prioridade de acesso aos recursos da União (De Oliveira, 2012).

A PNRS atribuiu aos municípios a gestão integrada dos resíduos sólidos gerados em seus territórios. Para tanto especificou uma série de instrumentos que poderiam ser utilizados, dentre eles o Plano Municipal de Gestão Integrada de Resíduos Sólidos (PMGIRS) recebe destaque (Brasil, 2010). Onde, a elaboração dos PMGIRS é condição necessária para o Distrito Federal e os municípios terem acesso aos recursos da União, destinados à limpeza urbana e ao manejo de resíduos sólidos (MMA, 2012). O PMGIRS pode estar inserido no Plano de Saneamento Básico integrando-se com os planos de água, esgoto, drenagem urbana e resíduos sólidos, previstos na Lei n ${ }^{\circ} 11.445$, de 2007. Neste caso deve ser respeitado o conteúdo mínimo definido em ambos os documentos legais (MMA, 2012).

A Lei 12.305/2010 Art. $3^{\circ}$ Inciso IX define geradores de resíduos sólidos como sendo pessoas físicas ou jurídicas, de direito público ou privado, que geram resíduos sólidos por meio de suas atividades, nelas incluído o consumo (Brasil, 2010). 
Sendo os grandes geradores os responsáveis por todo o gerenciamento dos resíduos incluindo a separação, o acondicionamento, a coleta, o tratamento e a disposição final ambientalmente adequada. A instrução normativa do SLU ${ }^{\circ} 89$, de 23 de setembro de 2016, reforça que o material deve ser tratado de maneiras diferentes. Os resíduos não recicláveis devem ser separados dos resíduos recicláveis secos e os orgânicos, e precisam ser identificados com etiqueta simples no saco (Brasil, 2016).

Diante disso, tendo em vista os benefícios que o gerenciamento adequado dos resíduos sólidos urbanos está totalmente ligado com a forma em que o poder público e a população se responsabilizam pela sua separação, o acondicionamento, a coleta, o tratamento e a disposição final desses resíduos. O presente trabalho tem o objetivo de fazer um levantamento da situação da destinação dos resíduos sólidos urbanos na região central do Município de Balsas, no Maranhão, relacionado aos grandes geradores.

\section{Metodologia}

\subsection{Caracterização da área de estudo}

O presente estudo foi-se realizado no município de Balsas (Figura 1) (07 31' 58" S; 46 02' 09" O) localizado na mesorregião sul Maranhense do Estado do Maranhão e possui população estimada de 95.929 habitantes e área de 13 141,637 $\mathrm{km}^{2}$, conforme dados do IBGE (2020).

Figura 1: Mapa de localização do município de Balsas-MA.

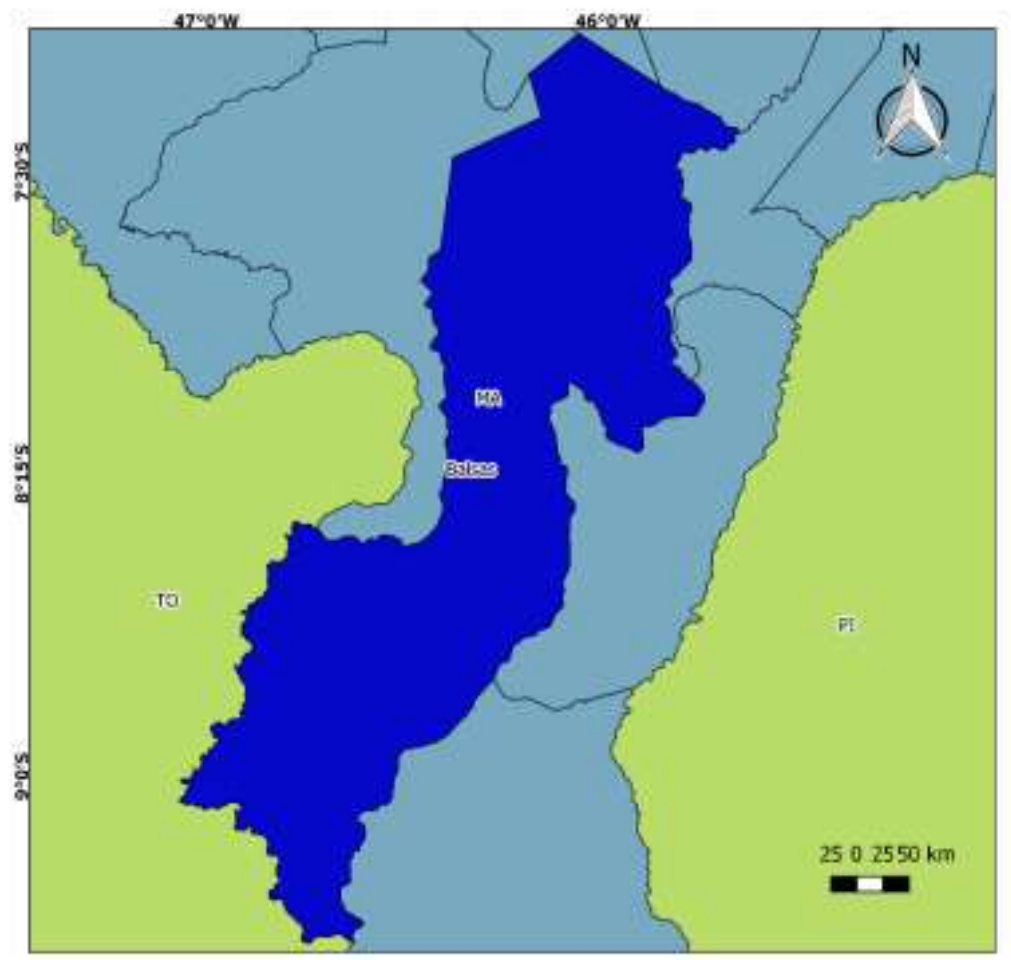

Fonte: Autores.
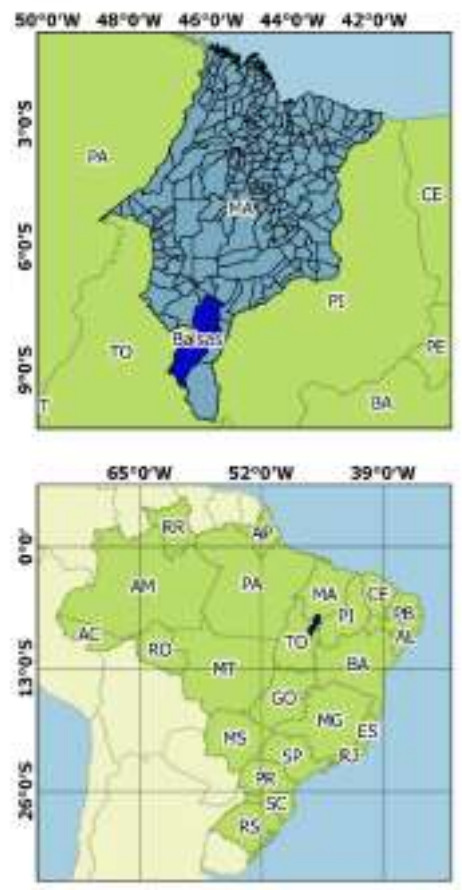

Em virtude de a área central do município concentrar a maior parte dos estabelecimentos comerciais, foi feita uma delimitação da área de estudo nesta região, como pode ser observado na Figura 2. 
Figura 2: Mapa de delimitação da área de estudo de Balsas-MA.

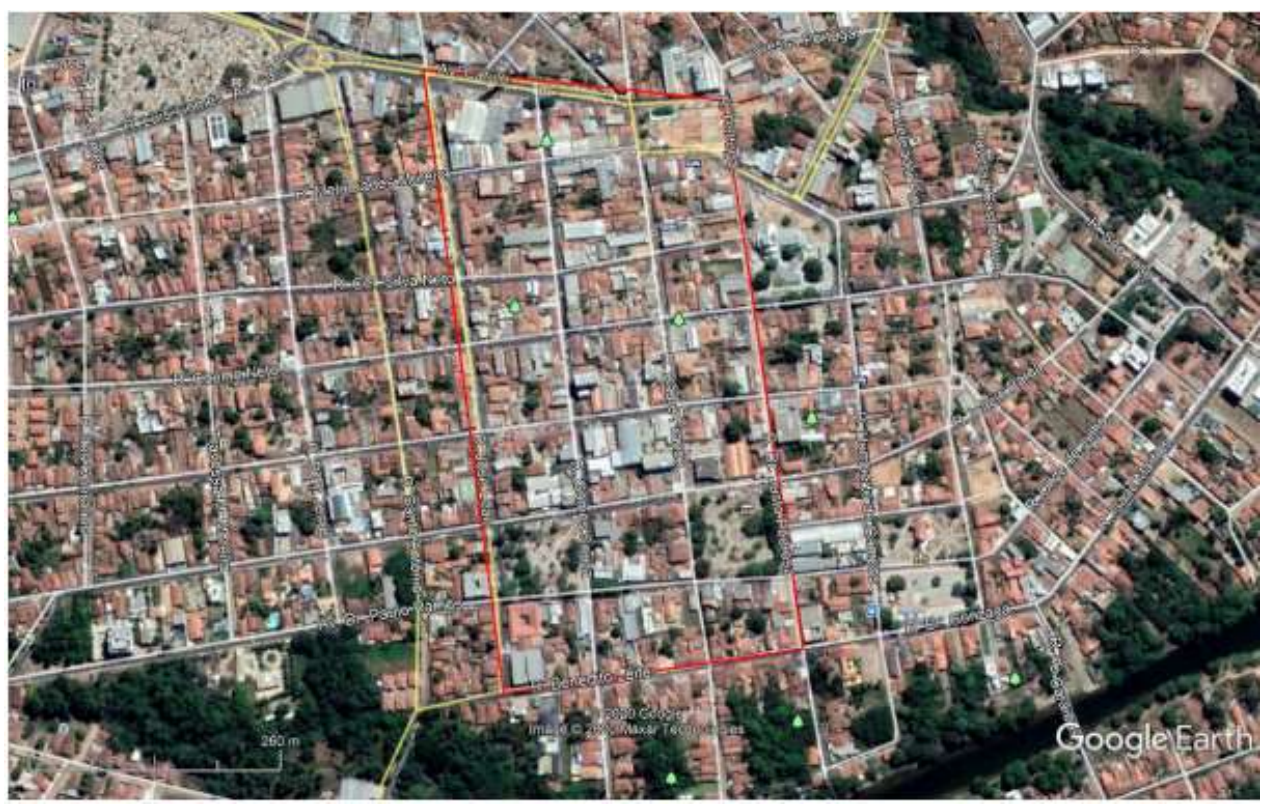

Fonte: Adaptado de Google Earth.

A área abrangida na pesquisa possui 195,56 quilômetros quadrados e inclui 21 quadras, onde 43 estabelecimentos foram entrevistados. Dentre eles estão clínicas médicas e odontológicas; o Hospital Balsas Urgente; restaurantes, incluindo o Restaurante Popular Municipal; supermercados; bancos; escritórios de advocacia; entre outros.

\subsection{Metodologia de pesquisa}

O trabalho consiste de pesquisa descritiva quali-quantitativa dos resíduos sólidos urbanos na área central do município, produzidos por empreendimentos comerciais. Então, conforme descrito em Estrela (2018), foi realizado o levantamento de coleta de dados em estabelecimentos comerciais geradores de resíduos sólidos urbanos no centro do município de Balsas-MA, e apontado por meio de pesquisa a quantidade e tipo de resíduo gerado, além da identificação da disposição final desses resíduos sólidos urbanos.

\subsection{Procedimentos metodológicos}

O delineamento deste estudo fundamentou-se na análise da legislação vigente no Brasil acerca do gerenciamento de resíduos sólidos, dos conceitos abordados na literatura atual e dos princípios e diretrizes da Lei 12.305, e sobretudo, a responsabilidade dos grandes geradores. Para melhor eficiência no recolhimento de dados efetuou-se um diagnóstico utilizando um questionário via Google Forms, que foi aplicado ao trabalhador responsável pela empresa/empreendimento da área de estudo delimitada. O modelo de questionário para obter a coleta de dados foi adaptado de Da Veiga (2015). O Quadro 1 mostra as perguntas utilizadas no questionário sobre identificação e caracterização dos grandes geradores da região central do município de Balsas-MA. 
Quadro 1: Listas de perguntas realizadas aos entrevistados.

\begin{tabular}{|c|c|}
\hline PERGUNTAS/TIPO DE RESPOSTAS & RESPOSTAS \\
\hline $\begin{array}{l}\text { 1. Quanto aos TIPOS de resíduos gerados nesse } \\
\text { empreendimento assinale aqueles que são produzidos } \\
\text { neste empreendimento/ serviço. (Múltipla escolha) }\end{array}$ & $\begin{array}{c}\square \text { Resíduos Biológicos } \\
\square \text { Resíduos Químicos } \\
\square \text { Resíduos Radioativos } \\
\square \text { Resíduos Perfurocortantes } \\
\square \text { Resíduos comuns (não contaminantes) } \\
\end{array}$ \\
\hline $\begin{array}{l}\text { 2. A quantidade gerada semanalmente destes resíduos } \\
\text { (Resposta única) }\end{array}$ & $\begin{array}{c}\square 0-10 \mathrm{~kg} \\
\square 11-29 \mathrm{~kg} \\
\square 30-50 \mathrm{~kg} \\
\square 51-120 \mathrm{~kg} \\
\square \text { Acima de } 120 \mathrm{~kg}\end{array}$ \\
\hline $\begin{array}{l}\text { 3. Quanto a segregação (separação) dos Resíduos gerados } \\
\text { (Resposta única) }\end{array}$ & $\begin{array}{l}\square \text { É realizada no local de sua geração } \\
\square \text { É realizada posteriormente } \\
\square \text { Não é realizada } \\
\square \text { Não tenho conhecimento } \\
\square \text { Outro: }\end{array}$ \\
\hline $\begin{array}{l}\text { 4. Quanto à coleta interna (recolhimento dos resíduos das } \\
\text { lixeiras, fechamento do saco e seu transporte até a sala } \\
\text { de resíduos ou expurgo) quem é responsável pela coleta } \\
\text { interna dos resíduos gerados neste empreendimento/ } \\
\text { serviço? (Múltipla escolha) }\end{array}$ & $\begin{array}{c}\square \text { Funcionário de serviço terceirizado } \\
\square \text { Funcionário do quadro funcional da Instituição } \\
\square \text { Não tenho conhecimento } \\
\square \text { Outro: }\end{array}$ \\
\hline $\begin{array}{l}\text { 5. Quanto à coleta externa (recolhimento dos resíduos } \\
\text { armazenados nas unidades a serem transportados para o } \\
\text { tratamento ou disposição final) quem é responsável pela } \\
\text { coleta externa dos resíduos gerados neste } \\
\text { empreendimento/ serviço? (Múltipla escolha) }\end{array}$ & $\begin{array}{c}\square \text { Prefeitura municipal } \\
\square \text { Lrq - laboratório de resíduos químicos } \\
\square \text { Empresa especializada; especificar } \\
\square \text { Não tenho conhecimento } \\
\square \text { Outro: }\end{array}$ \\
\hline $\begin{array}{l}\text { 6. Quanto à destinação final: qual é o tipo de destinação } \\
\text { final dada aos resíduos gerados neste empreendimento/ } \\
\text { serviço? (Múltipla escolha) }\end{array}$ & $\begin{array}{c}\square \text { Aterro sanitário } \\
\square \text { Aterro industrial } \\
\square \text { Vala séptica } \\
\square \text { Dispostos diretamente no solo } \\
\square \text { Queimados } \\
\square \text { Não tenho conhecimento } \\
\square \text { Outro: }\end{array}$ \\
\hline
\end{tabular}

Fonte: Autores.

As questões abordadas no questionário foram adaptadas a fim de fornecer informações que auxiliassem na elaboração do diagnóstico referente a identificação, geração e manejo dos resíduos gerados pelos grandes geradores. Critérios fundamentais como o conteúdo, tamanho, organização e clareza das questões, foram observados para estimular o informante a responder às questões abordadas com fácil compreensão (Barros; Lehfeld, 1986).

Dessa forma, o processo do desenvolvimento deste trabalho deu-se por etapas, as quais temos:

Etapa I - Elaboração do questionário avaliativo: Foi desenvolvido um questionário, adaptado de De Veiga (2015), para os grandes geradores de resíduos sólidos urbanos no centro do município. As questões abordadas no questionário foram adaptadas a fim de fornecer informações que auxiliassem na elaboração do diagnóstico.

Etapa II - Aplicação do questionário avaliativo: O questionário foi aplicado diretamente aos funcionários/proprietários de 42 empreendimentos/estabelecimentos da região selecionada, no período de 14 de setembro a 8 de outubro de 2020 .

Etapa III - Coleção dos dados: Depois de aplicado o questionário, todas as respostas obtidas foram tabuladas para análise.

Etapa IV- Qualificação e quantificação dos dados: Após a etapa de coleta de dados foi possível realizar a qualificação e quantificação dos mesmos quanto a: os tipos de resíduos gerados; a forma em que são separados; o tipo de coleta (interna e/ou externa); e a disposição final dada. 
Logo após essas etapas, os dados foram tabulados em programas como Microsoft Excel e Word e por fim analisados os tipos de resíduos encontrados, a quantidade gerada semanalmente, a forma que é feita o acondicionamento, os responsáveis pela coleta interna e externa e a destinação final dada a esses resíduos.

\section{Resultados e Discussão}

Por meio do levantamento realizado no centro da cidade de Balsas, foi possível identificar tipos de resíduos encontrados, a quantidade gerada semanalmente, a forma que é feita a separação, os responsáveis pela coleta interna e externa e a destinação final dada a esses resíduos.

Através do questionário aplicado aos estabelecimentos foi possível identificar os tipos de resíduos gerados na área delimitada da região central. A Figura 3 mostra o número de estabelecimentos e os tipos de resíduos.

Figura 3: Tipos de resíduos produzidos nos empreendimentos/serviços.

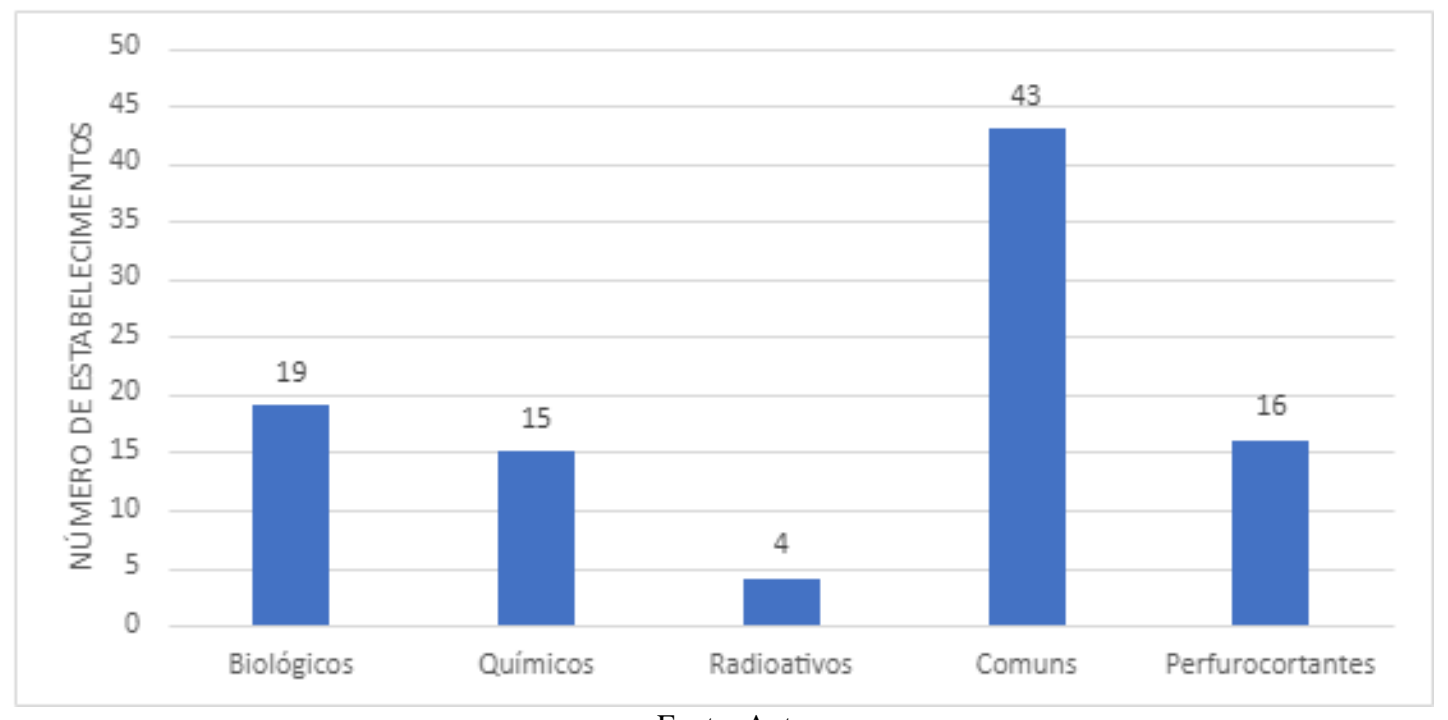

Fonte: Autores.

Analisando a Figura 3 percebe-se que todos os estabelecimentos geram resíduos comuns. Onde 19 geram resíduos biológicos; 16 perfurocortantes; 15 resíduos químicos; e 4 geram resíduos radioativos. Alguns empreendimentos geram mais de um tipo de resíduo. De acordo com a Lei na 12.305/2010, no Título III, a classificação desses resíduos é determinada quanto à sua origem e periculosidade. A caracterização irá identificar o processo/atividade que deu origem a este resíduo, além de seus constituintes e características que podem causar impacto à saúde e ao meio ambiente (ABNT, 2004).

Conforme Araújo e Silva (2020) os resíduos sólidos podem ser veículo de transmissão de doenças, como a COVID19, apresentando riscos para a população e para os operadores que trabalham de diferentes formas e esses riscos podem ser agravados em áreas com falta ou precariedade de saneamento básico, seja na coleta, tratamento e disposição final.

O município de Balsas não dispõe de legislação específica para a definição dos grandes geradores, tomando como base a Lei 5.610/16, para esta definição são considerados grandes geradores pessoas físicas ou jurídicas que produzam resíduos em estabelecimentos comerciais, públicos, de prestação de serviço, terminais rodoviários e aeroportuários, cuja natureza ou composição sejam similares àquelas dos resíduos domiciliares e cujo volume diário seja superior em média a 120 litros. É importante ressaltar que a caracterização dos grandes geradores irá variar de acordo com as características locais de cada município. A Figura 4 apresenta as quantidades produzidas nos estabelecimentos analisados em Balsas. 
Figura 4: Quantidade de resíduos gerados nos empreendimentos/serviços.

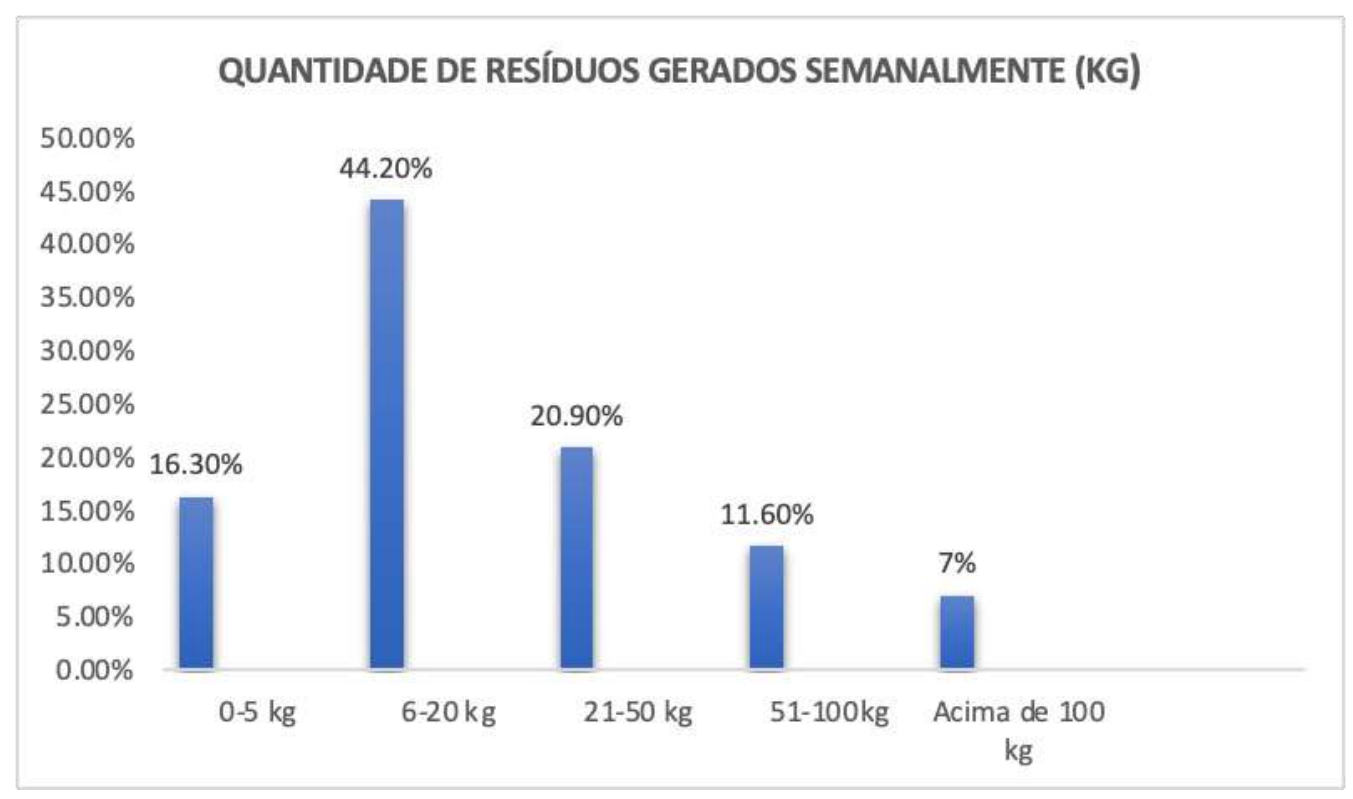

Fonte: Autores.

A Figura 4, apresenta a quantidade gerada semanalmente, onde 19 dos estabelecimentos $(44,2 \%)$ produzem de 6-20 $\mathrm{kg} ; 9(20,9 \%)$ geram entre 21-50 kg; 7 (16,3\%) geram entre 0-5 kg; $5(11,6 \%)$ geram entre 51-100 kg; 3 (7\%) produzem acima de $100 \mathrm{~kg}$. Para se determinar quais estabelecimentos/empreendimentos seriam considerados grandes geradores a partir da quantidade de resíduos que estes produzem, seria necessário fazer uma análise gravimétrica destes resíduos, para então se determinar as características locais, e por fim, se determinar os grandes geradores.

Em estudos realizados por Poletto (2018) avaliou-se os grandes geradores do município de Florianópolis e constatouse que quase 10 mil estabelecimentos não possuem Legislação que os diferencie entre grandes e pequenos geradores de resíduos. Com isso, os empreendimentos seguem uma proposta de alteração de Lei Complementar Municipal que define como grandes geradores as unidades imobiliárias que gerem uma quantidade de resíduos sólidos superior a 100 litros diários de recicláveis secos, 20 litros diário de resíduos sólidos orgânicos e 50 litros diários de rejeitos. Já o trabalho de Steiner (2010), com relação a gestão de resíduos sólidos em centros comerciais em Curitiba/PR, destaca que o Art. $8^{\circ}$ do Decreto Municipal de Curitiba/PR 983/04 estabelece que os grandes geradores são os empreendimentos que geram resíduos orgânicos acima de 600 L/semana e recicláveis acima de 600 L/semana. Ambas as pesquisas apontam a importância da delimitação das características dos grandes geradores de acordo com as características locais.

Parte importante do manejo de resíduos refere-se a segregação, a Figura 5 apresenta o tipo de segregação aplicado pelos empreendimentos da região central do município. 
Research, Society and Development, v. 10, n. 10, e383101019103, 2021

(CC BY 4.0) | ISSN 2525-3409 | DOI: http://dx.doi.org/10.33448/rsd-v10i10.19103

Figura 5: Quantidade de resíduos gerados nos empreendimentos/serviços.

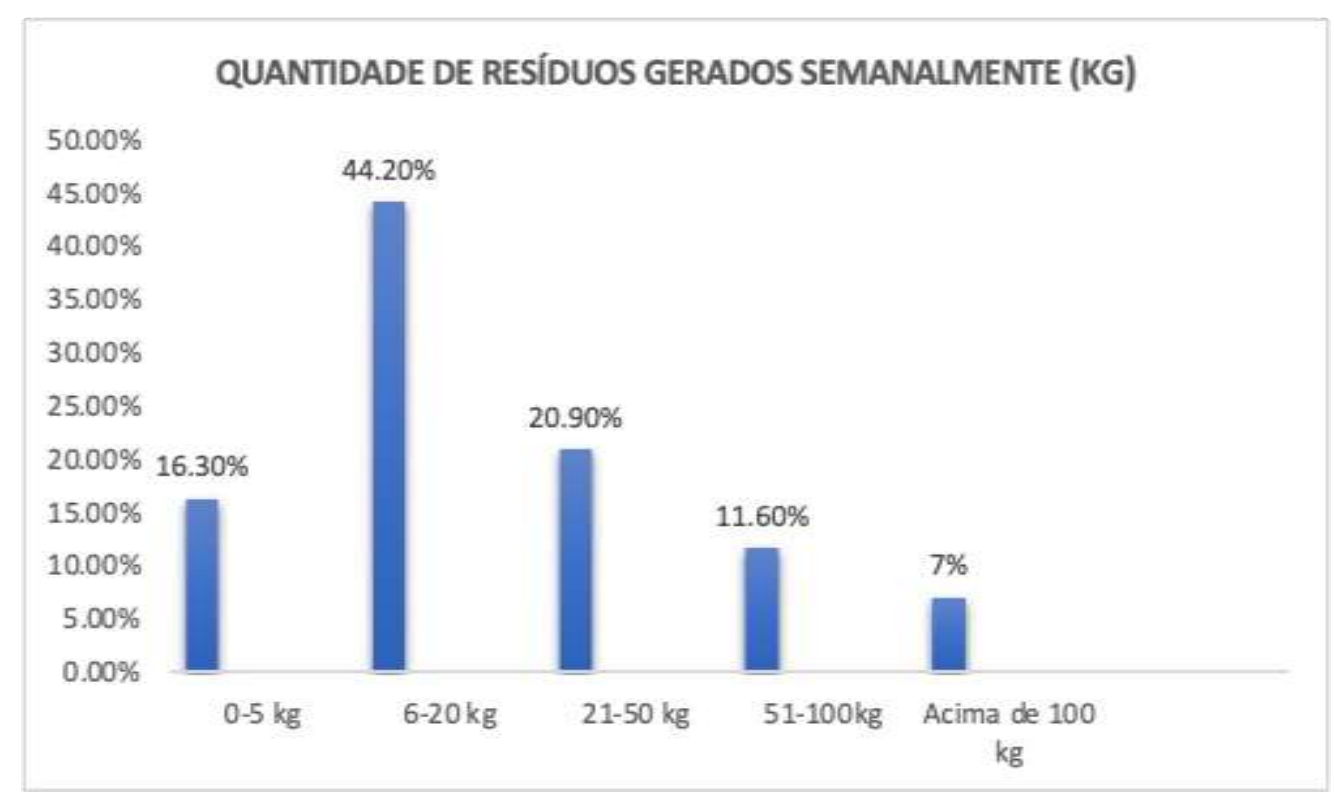

Fonte: Autores.

A Figura 5, apresenta a quantidade gerada semanalmente, onde 19 dos estabelecimentos (44,2\%) produzem de 6-20 $\mathrm{kg} ; 9$ (20,9\%) geram entre 21-50 kg; 7 (16,3\%) geram entre 0-5 kg; 5 (11,6\%) geram entre 51-100 kg; 3 (7\%) produzem acima de $100 \mathrm{~kg}$. Para se determinar quais estabelecimentos/empreendimentos seriam considerados grandes geradores a partir da quantidade de resíduos que estes produzem, seria necessário fazer uma análise gravimétrica destes resíduos, para então se determinar as características locais, e por fim, se determinar os grandes geradores.

Em estudos realizados por Poletto (2018) avaliou-se os grandes geradores do município de Florianópolis e constatouse que quase 10 mil estabelecimentos não possuem Legislação que os diferencie entre grandes e pequenos geradores de resíduos. Com isso, os empreendimentos seguem uma proposta de alteração de Lei Complementar Municipal que define como grandes geradores as unidades imobiliárias que gerem uma quantidade de resíduos sólidos superior a 100 litros diários de recicláveis secos, 20 litros diário de resíduos sólidos orgânicos e 50 litros diários de rejeitos. Já o trabalho de Steiner (2010), com relação a gestão de resíduos sólidos em centros comerciais em Curitiba/PR, destaca que o Art. $8^{\circ}$ do Decreto Municipal de Curitiba/PR 983/04 estabelece que os grandes geradores são os empreendimentos que geram resíduos orgânicos acima de 600 L/semana e recicláveis acima de $600 \mathrm{~L} / \mathrm{semana}$. Ambas as pesquisas apontam a importância da delimitação das características dos grandes geradores de acordo com as características locais.

Parte importante do manejo de resíduos refere-se a segregação, a Figura 6 apresenta o tipo de segregação aplicado pelos empreendimentos da região central do município. 
Research, Society and Development, v. 10, n. 10, e383101019103, 2021

(CC BY 4.0) | ISSN 2525-3409 | DOI: http://dx.doi.org/10.33448/rsd-v10i10.19103

Figura 6: Segregação dos resíduos gerados nos empreendimentos/serviços.

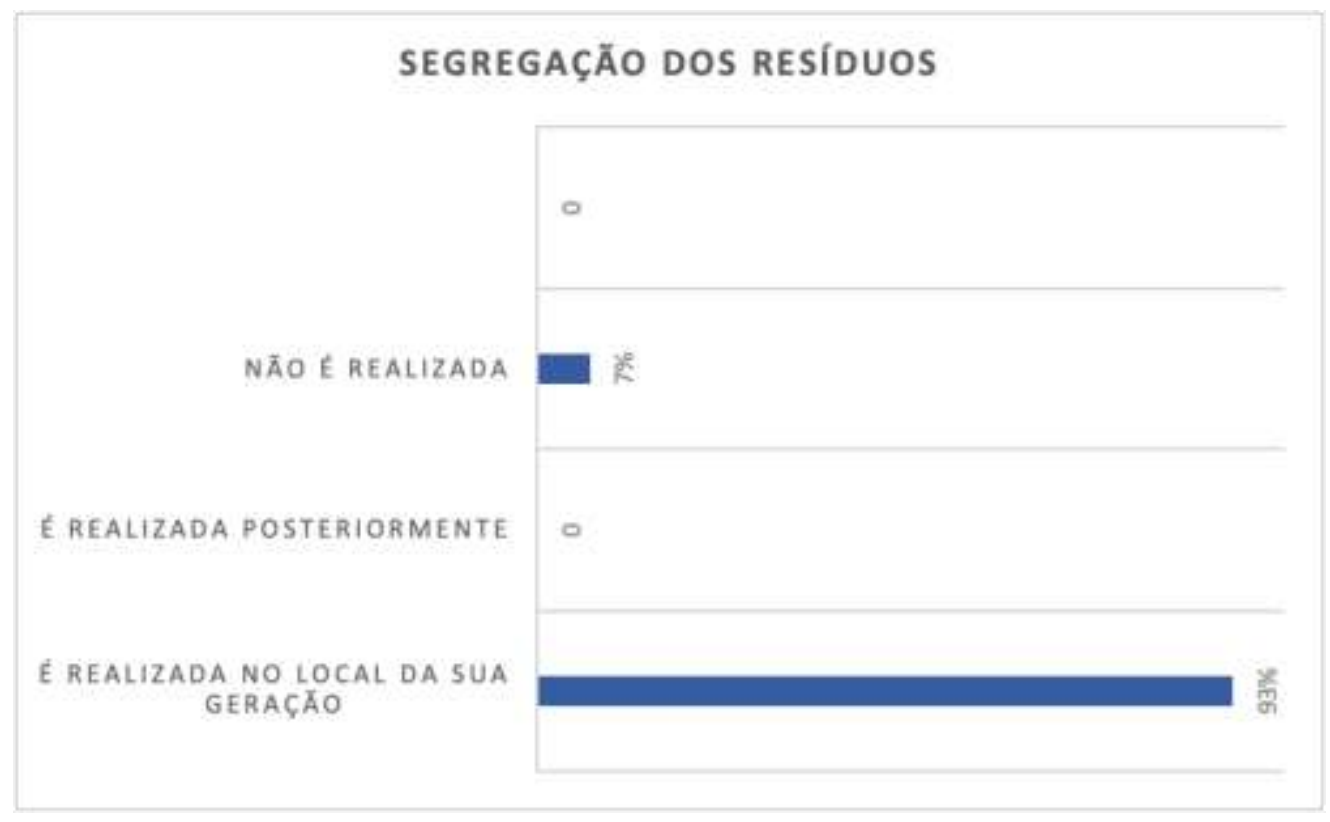

Fonte: Autores.

Com base na Figura 6 é possível determinar que a separação desses resíduos nos estabelecimentos é, em sua grande maioria, realizada no local de sua geração, que contabilizam 93\% dos estabelecimentos visitados, sendo que $7 \%$ desses estabelecimentos/empreendimentos não fazem nenhum tipo de segregação. Esta é a etapa que exige maior adesão dos usuários, com uma mudança de hábito no momento do descarte do lixo (Rodrigues, 2016). A separação na fonte geradora dos resíduos conforme suas características, é de suma importância, pois dá maior eficiência para as demais etapas de gerenciamento, evitando a contaminação de quantidades significativas de materiais reaproveitáveis em decorrência da mistura de resíduos (Zanta e Ferreira, 2003).

Conforme Pereira (2019) na cidade de São Paulo foi elaborado em 2014 o Plano de Gestão Integrada de Resíduos Sólidos (PGIRS) e trouxe um diagnóstico do gerenciamento de resíduos sólidos para a cidade e diretrizes para serem cumpridas para o futuro, possuindo uma meta de 100\% para a segregação de resíduos secos até o ano de 2022.

De acordo com Funasa (2006), o planejamento e a organização de um bom sistema de coleta são fundamentais. De um modo geral a coleta e transporte devem garantir uma regularidade da coleta: os resíduos sólidos devem ser recolhidos em períodos regulares (periodicidade); intervalo entre uma coleta e a seguinte, deve ser o mais curto possível (frequência); e horário (usualmente a coleta é feita durante o dia). A Figura 7 demonstra quem são os responsáveis pela coleta interna nos estabelecimentos: 
Research, Society and Development, v. 10, n. 10, e383101019103, 2021

(CC BY 4.0) | ISSN 2525-3409 | DOI: http://dx.doi.org/10.33448/rsd-v10i10.19103

Figura 7: Responsável pela coleta interna dos resíduos produzidos nos estabelecimentos.

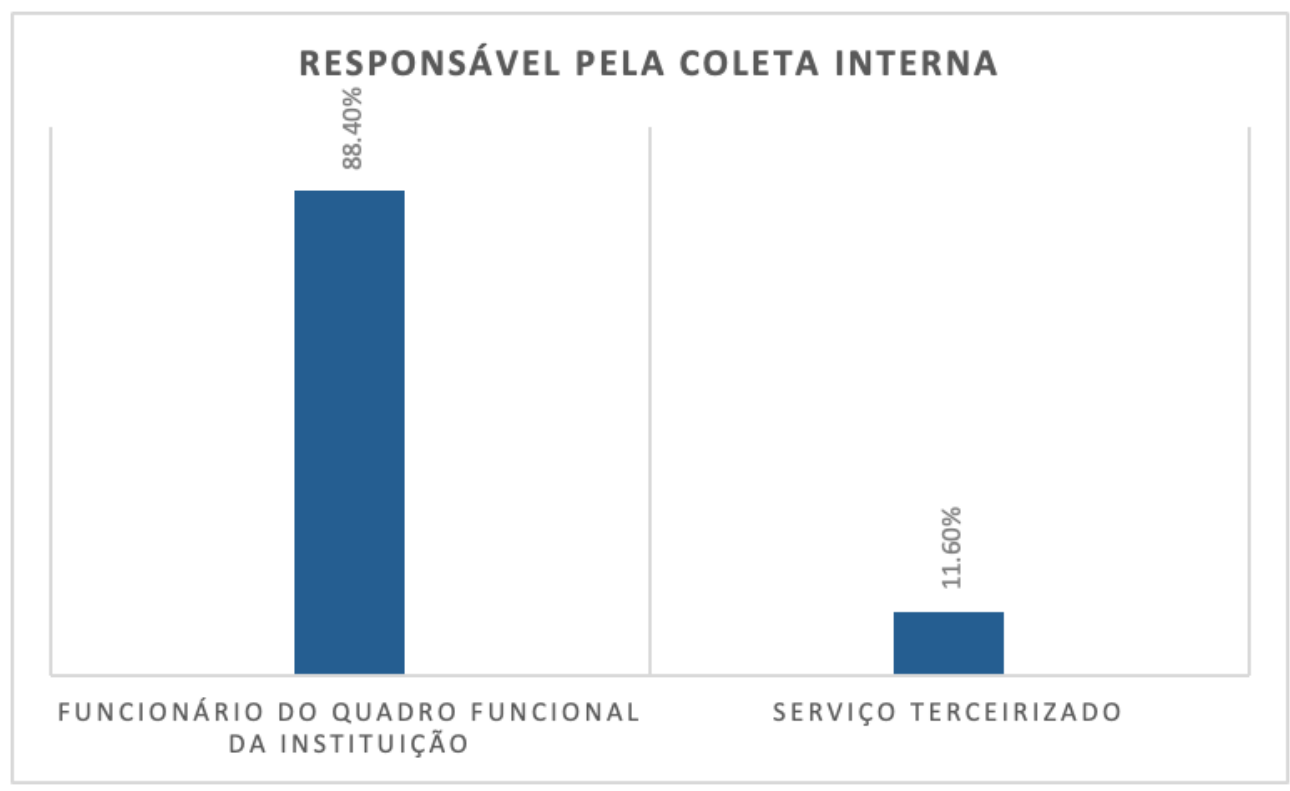

Fonte: Autores.

Conforme mostra a Figura 7, em todos os empreendimentos avaliados, a pessoa entrevistada sabe de quem é a responsabilidade do recolhimento dos resíduos das lixeiras, fechamento do saco e transporte até a área de armazenamento temporário de resíduos (coleta interna), em 88,4\% dos estabelecimentos é de responsabilidade de funcionários do quadro da instituição e $11,6 \%$ é responsabilidade de funcionários de serviço terceirizado.

A falta de uma legislação específica que caracterize os grandes geradores de resíduos sólidos urbanos no município de Balsas faz com que a maior parte da coleta externa seja realizada pela Prefeitura Municipal, como é mostrado na Figura 8.

Figura 7: Responsável pela coleta externa dos resíduos produzidos nos estabelecimentos.

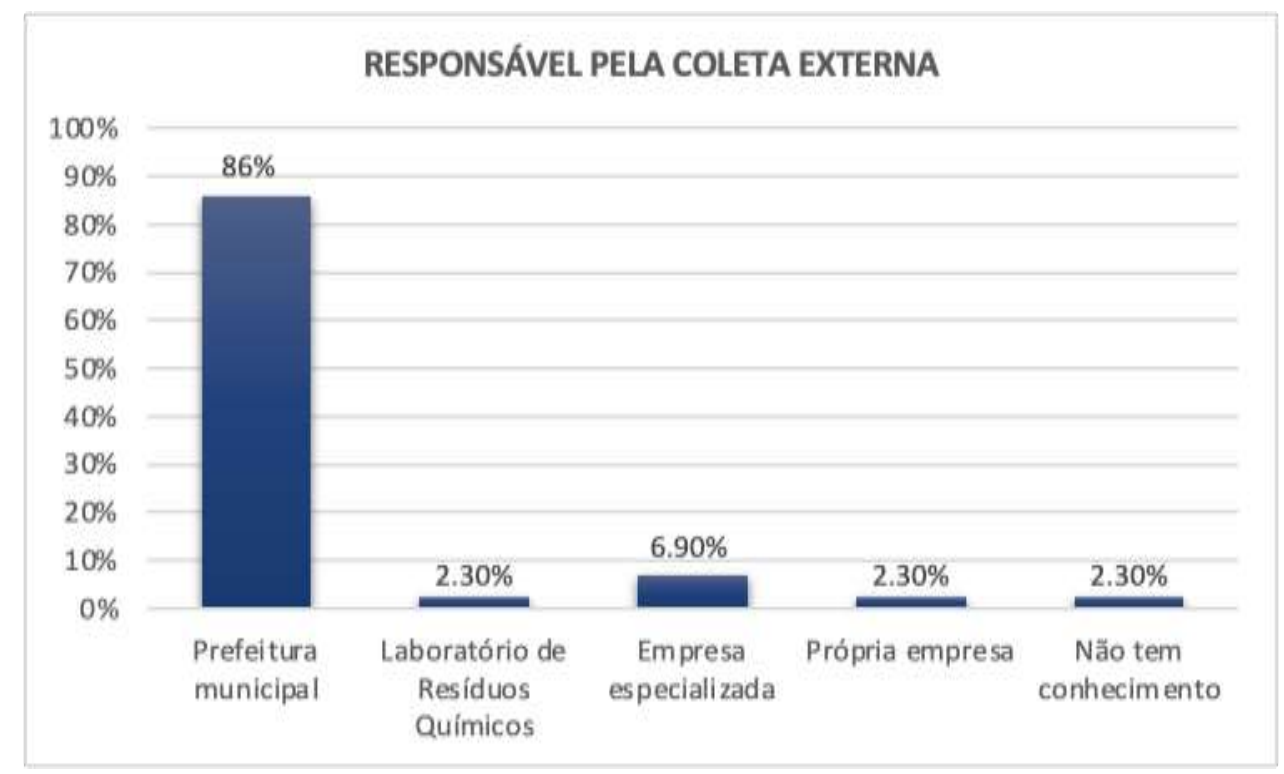

Fonte: As autoras. 
A Figura 7 evidencia que $86 \%$ dos estabelecimentos tem seus resíduos coletados pela prefeitura municipal. O problema é causado principalmente porque não há legislação específica que defina normas de responsabilidade aos grandes geradores sobre os resíduos por estes gerados; 6,9\% possuem uma empresa especializada na sua coleta; 2,3\% é responsabilidade do Laboratório de Resíduos Químicos; 2,3\% é responsabilidade da própria empresa; 2,3\% não tem conhecimento. Do percentual total de empreendimentos que contratam empresa especializada para a destinação final dos resíduos sólidos, 58,1\% não tem conhecimento se é feito algum registro de informações de transporte desses resíduos desde a fonte geradora até a destinação final para monitoramento; 9,3\% faz um registro de informações; e 32,6\% não faz esse monitoramento.

Segundo CEMPRE (2018), 88\% dos municípios realizam coleta de porta em porta, sendo esta, responsabilidade da prefeitura municipal. Com relação ao município de Balsas, como ainda não há legislação específica que caracterize os grandes geradores de RSU a maior parte da coleta é realizada pela Prefeitura Municipal que poderia ter seus custos de coleta reduzidos caso os grandes geradores fossem identificados e responsáveis pelos resíduos gerados. A coleta externa podendo ser de responsabilidade pública (pequenos geradores) e privada (grandes geradores).

A disposição final consiste na última etapa do manejo e dependerá de cada tipo de resíduo. Cerca de $60 \%$ das cidades brasileiras alocam quase 30 milhões de toneladas de lixo em locais impróprios segundo o Panorama dos Resíduos Sólidos no Brasil, produzido pela Associação Brasileira de Empresas de Limpeza Pública e Resíduos Especiais (ABRELPE), em 2015. Dessa forma, o tipo de destinação final dada aos resíduos gerados, é apresentado na Figura 8:

Figura 8: Disposição final dada aos resíduos produzidos nos empreendimentos/serviços.

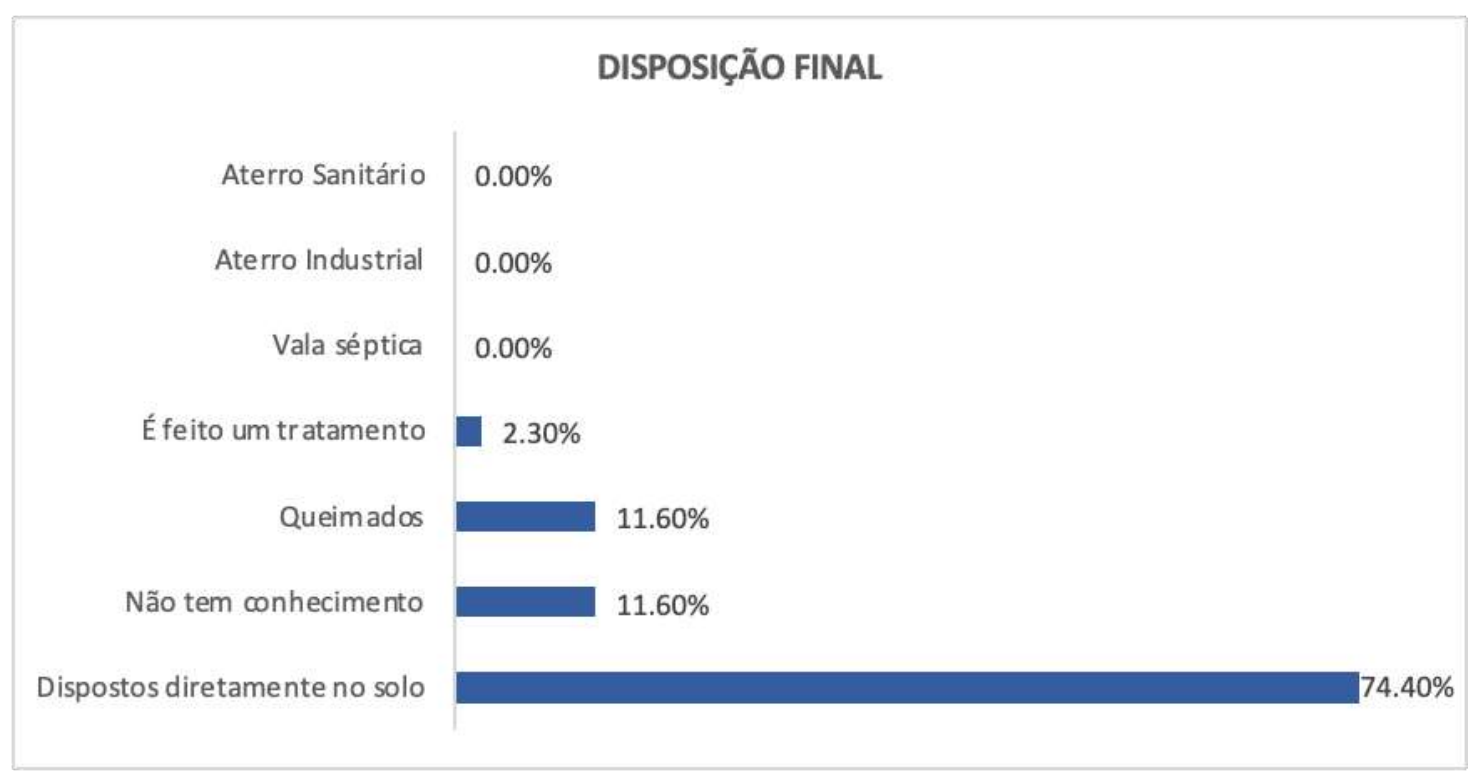

Fonte: Autores.

Conforme mostra a Figura 8, 74,4\% dos resíduos produzidos são dispostos diretamente no solo; 11,6\% são queimados (totalmente inadequado); 11,6\% não tem conhecimento; e 2,3\% é feito um tratamento. Percebe-se que a maior parte dos resíduos produzidos nestes estabelecimentos são dispostos de forma inadequada em lixões. Conforme Cempre (2018) o problema da destinação final dos resíduos sólidos urbanos está presente em $92 \%$ dos municípios da região nordeste, e também é uma realidade no município de Balsas. Segundo a Abrelpe (2014), no Brasil quase 34 mil toneladas de resíduos por dia foram destinadas a lixões, o que caracteriza um quadro preocupante de poluição ambiental, além da exposição de pessoas a diversas doenças e vários tipos de contaminações graves. 
No trabalho de Vargas (2020), que foi realizado em Porto Alegre-RS demonstra que 61,6\% dos resíduos gerados na cidade são destinados a reciclagem, possuindo um aproveitamento de $92 \%$ desse material que foi reciclado, que fazendo uma comparação com o município de Balsas é possível notar que se no município fosse implantado a coleta seletiva grande parte dos resíduos que são dispostos diretamente no solo (lixão) e não são aproveitados e/ ou reaproveitados poderiam ser reciclados diminuindo a quantidade de rejeitos gerados e assim diminuiria o impacto ambiental que é causado.

Para determinar o melhor tratamento e/ou disposição final dos resíduos gerados, é necessário que haja controle e estimativa da quantidade gerada, além do conhecimento da frequência da coleta externa de cada tipo de resíduo.

De acordo com o IBGE, 2007, de todos os resíduos coletados, cerca de: 3,6\% são destinados aos aterros sanitários; 21,2\% são encaminhados a lixões; $4,3 \%$ são destinados a estações de triagem, compostagem ou incineração e o restante, pouco mais de $70 \%$, está relacionado a outro destino final como, por exemplo, aterros controlados. Os aterros sanitários, são considerados tecnicamente a solução mais indicada para a disposição final dos resíduos sólidos. E, de acordo com pesquisas existentes, é a melhor e mais barata forma de disposição final de resíduos sólidos (Zanta e Ferreira, 2003).

\section{Considerações Finais}

Através da pesquisa, buscou-se investigar de que forma é realizado o gerenciamento dos resíduos sólidos urbanos pelos empreendimentos que se enquadrariam como grandes geradores na área central do município de Balsas. $\mathrm{O}$ estudo mostrou a necessidade que o município tem em implantar a legislação específica com relação a reponsabilidade dos grandes geradores quanto aos resíduos que estes produzem, de forma a contribuir com as prerrogativas da Política Nacional dos Resíduos Sólidos, que destaca a responsabilidade destes desde a fase de manejo até a destinação final dos seus resíduos.

Tal fato foi comprovado, uma vez que a grande maioria dos empreendimentos/ estabelecimentos (86\%) no centro do município abstém-se de suas responsabilidades sobre o gerenciamento destes resíduos, encaminhando essa responsabilidade para a Prefeitura Municipal, que é a responsável pela coleta externa e destinação final dos resíduos da maior parte dos estabelecimentos.

Além disso, constatou-se falhas no sistema de gerenciamento destes resíduos e disposição final inadequada, e isso ocorre principalmente em função do comportamento da população e da negligência dos gestores em relação ao descarte inadequado em lixões, uma vez que o gerenciamento integrado conforme a Lei 12.305/2010 revela-se como responsabilidade não só do poder público, mas também dos demais agentes envolvidos na gestão, desde a população, que deveria fazer a separação e acondicionamento adequado; os grandes geradores, responsáveis pelos próprios rejeitos; os catadores, organizados em cooperativas; os estabelecimentos que tratam da saúde, separando adequadamente os resíduos perigosos e os comuns; e a prefeitura, através de seus agentes, instituições e empresas contratadas.

Dessa forma, o procedimento de coleta e destinação final dos RSU produzidos pelos grandes geradores, apresenta-se como um dos maiores desafios a serem enfrentados, e sua importância deve-se principalmente a responsabilidade da coleta externa ser feita pela prefeitura municipal ( $86 \%$ dos estabelecimentos) e essa faz a deposição diretamente no solo, sendo uma forma inadequada, causando impactos ao meio ambiente e à saúde da população.

Por fim, espera-se que o poder público municipal proporcione a adequação do Plano de Gerenciamento de Resíduos Sólidos do Município junto às legislações brasileiras vigentes, reforçando o seu comprometimento social e ambiental perante a sociedade, e que sobretudo, o estudo possa propiciar um estímulo para se determinar as responsabilidade dos grandes geradores quanto aos resíduos que estes produzem, para que o gerenciamento destes esteja de acordo com o que preconiza a Lei 12.305/2010, considerando a variedade e a especificidade dos tipos de resíduos produzidos pelos grandes geradores. 
Em trabalhos futuros, espera-se que seja realizada a utilização de análise gravimétrica dos resíduos gerados no município, incluindo toda a área urbana, que permitirá a possibilidade de reaproveitamento dos resíduos sólidos urbanos gerados, avaliando o potencial de reciclagem desses resíduos, a destinação final adequada e assim fornecer subsídios para a melhora do gerenciamento dos resíduos sólidos da cidade.

\section{Referências}

ABNT, N. (2004). 10004: 2004. Resíduos sólidos: Classificação. Associação Brasileira de Normas.

ABRELPE - Associação Brasileira De Empresas De Limpeza Pública E Resíduos Especiais, (2012). Associação Brasileira de Empresas de Limpeza Pública e Resíduos Especiais. Panorama dos resíduos sólidos no Brasil. https://abrelpe.org.br/download-panorama-2012/

ABRELPE, - Associação Brasileira De Empresas De Limpeza Pública E Resíduos Especiais. (2014). Associação Brasileira de Empresas de Limpeza Pública e Resíduos Especiais. Panorama dos resíduos sólidos no Brasil. https://abrelpe.org.br/download-panorama-2014/

ABRELPE, - Associação Brasileira De Empresas De Limpeza Pública E Resíduos Especiais. (2015). Associação Brasileira de Empresas de Limpeza Pública e Resíduos Especiais. Panorama dos resíduos sólidos no Brasil. https://abrelpe.org.br/download-panorama-2015/

Araújo, E. C. D. S., \& Silva, V. F. (2020). A gestão de resíduos sólidos em época de pandemia do Covid-19.

Barros, A. D. J. P. D. \& Lehfeld, N. A. S. (1986). Fundamentos de Metodologia. McGrawHill Artmed.

Brasil. (2010). Política Nacional de Resíduos Sólidos. Lei nº 12.305, de 2 de agosto de 2010. Presidência da República Casa Civil. Subchefia para Assuntos Jurídicos.

CEMPRE - Compromisso Empresarial Para Reciclagem. (2018). Lixo municipal: manual de gerenciamento integrado. https://cempre.org.br/wpcontent/uploads/2020/11/6-Lixo_Município_2018.pdf/

Estrela, C. (2018). Metodologia científica: ciência, ensino, pesquisa. Artes Médicas.

Fundação Nacional de Saúde (Brasil). (2006). Manual de saneamento. Funasa.

IBGE - Instituto Brasileiro de Geografia e Estatística. (2007). Fundação Instituto Brasileiro de Geografia e Estatística (IBGE). Censo Agropecuário-2012.

IBGE - Instituto Brasileiro de Geografia e Estatística, (2020). - Instituto Brasileiro de Geografia e estatística. https://www.ibge.gov.br/cidades-eestados/ma/balsas.html.

Lei $n^{\circ} 5610$ de 16 de fevereiro de 2016 (2016). Dispõe sobre a responsabilidade dos grandes geradores de resíduos sólidos e dá outras providências. Câmara Legislativa do Distrito Federal. https://www.agenciabrasilia.df.gov.br/wp-conteudo/uploads/2016/09/lei-distrital-nr5610-2016.pdf

MMA - Ministério do Meio Ambiente. (28 de Agosto de 2012). Plano nacional de resíduos sólidos. https://antigo.mma.gov.br/cidades-sustentaveis/residuossolidos/instrumentos-da-politica-de-residuos/planos-municipais-de-gest\%C3\%A3o-integrada-de-res\%C3\%ADduos-s\%C3\%B3lidos/item/10332planonacionalrs.html

Oliveira, A. C. A. (2012). Gestão de resíduos sólidos: uma oportunidade para o desenvolvimento municipal e para as micro e pequenas empresas.

Pereira, E. V. (2019). Resíduos sólidos. Editora Senac São Paulo.

Poletto, L. D. (2018). Metodologia de definição de grandes geradores de resíduos sólidos urbanos para o município de florianópolis.

Rodrigues, D. C. (2016). Proposição de um plano de gerenciamento de resíduos sólidos para o Centro Integrado de Operação e Manutenção da CASAN (CIOM).

Steiner, P. A. (2010). Gestão de resíduos sólidos em centros comerciais do município de Curitiba-PR.

Vargas, R. R. (2020). Consumo sustentável: aperfeiçoamento das práticas de descarte de resíduos recicláveis.

Veiga, J. E. (2015). Para entender o desenvolvimento sustentável. Editora 34.

Zanta, V. M., \& Ferreira, C. F. A. (2003). Gerenciamento integrado de resíduos sólidos urbanos. AB de Castilho Júnior (Coordenador), Resíduos sólidos urbanos: aterro sustentável para municípios de pequeno porte. São Carlos, SP: Rima Artes e Textos. 